\title{
MISSIVAS: DIALOGISMO LITERARIO E INTERACCIÓN SOCIOCULTURAL
}

\author{
MISSIVES: LITERARY DIALOGISM AND SOCIOCULTURAL \\ INTERACCIÓN
}

\author{
Ana Cláudia Santos \\ Centro Universitário de Formiga, Brasil \\ https://orcid.org/0000-0003-2710-6000 \\ anaclaudiasantoss.acs@gmail.com
}

Recibido: 05-12-2019 Revisado: 13-12-2019 Aceptado: 09-01-2020

\begin{abstract}
Resumen: El presente artículo tiene como objetivo reflexionar y analizar los conceptos y los mecanismos que permiten organizar el pensamiento humano a través del lenguaje, expresando sus movimientos internos, para establecer dialogismos entre el arte literario, que aboga por varias manifestaciones ficticias sin perder la esencia de la verosimilitud, y la carta como un enlace entre los interlocutores, el gesto y el valor de la escritura. Para la fundamentación teórica las principales contribuciones son tomadas de Bakhtin (1997), Cosson (2006) y Foucault (1992). A través de la revisión bibliográfica, es posible percibir que los textos que sobrepasan el sentido de las palabras configuran estrategias dialógicas que acercan al emisor y al receptor, potenciando la idea de que la escritura conlleva a consecuencias sociales, culturales, políticas, económicas y cognitivas. Las cartas cuando se usan con fines didácticos, materializan diferentes saberes y sensaciones.
\end{abstract}

Palabras claves: Arte literario, lenguaje, cartas

\begin{abstract}
This article aims to reflect and analyze concepts and mechanisms that allow the organization of human thought through language and express internal movements, in order to establish dialogues between literary art - which advocates several fictional manifestations, without losing the essence of realism- and the letter as a link between the interlocutors, the gesture and the value of writing. For the theoretical basis, the main contributions are from Bakhtin (1997), Cosson (2006) and Foucault (1992). From the bibliographic review, it is possible to notice that the texts that go beyond the meaning of the words configure strategies for dialogue that bring the sender and the receiver closer together, enhancing the idea that writing brings social, cultural, political, economic, and cognitive consequences. Letters, when used for teaching purposes, produce different knowledge and feelings.
\end{abstract}

Keywords: Literary Art, language, missive

Cómo citar este artículo: Santos, A.Cl. (2020). Missivas. Dialogismo literario e interacción sociocultural. Hachetetepé. Revista cientifica en Educación y Comunicación, (20), 44-54.doi: http://doi.org/10.25267/Hachetetepe.2020.i20.6

\section{LENGUAJE E INTERACCIÓN SOCIAL}

El lenguaje es el resulta de la interacción social humana, posibilitando su adquisición y desarrollo. Es a partir del juego comunicativo que se aprende a operar el lenguaje, el hombre es capaz de colocarse como un interlocutor que inventa, crea y produce sentidos. Es a través del habla y de su expresión en las relaciones interpersonales que el mundo se hace realidad. Contar ideas representa la capacidad para crear y expresar el propio pensamiento $\mathrm{y}$, de cierto modo, recrear el propio individuo, el lenguaje y el pensamiento se sobreponen. El pensamiento esta individualizado e incluso internalizado, 
organizado solo en la lógica de la persona que lo produce; al escribir, lo implícito se vuelve explícito, es posible conocer mejor lo que antes solo se conocía de forma confusa.

El término lenguaje designa una facultad humana, es decir, la facultad de usar signos con fines cognitivos. El lenguaje es un dispositivo que caracteriza a la especie humana como homo sapiens, es decir, como sujeto reflexivo, porque a través del lenguaje logramos ser seres racionales. Por lo tanto, el lenguaje es un fenómeno humano, hoy considerado innato y genéticamente transmitido por la especie (Dionisio y Bezerra, 2003, p.22).

El lenguaje presupone experiencias compartidas, la lectura y la escritura son prácticas recurrentes en cualquier sociedad alfabetizada. Diariamente, el sujeto se ve a sí mismo como un emisor-receptor de información la cual transmite en todo momento, es incentivado constantemente a compartir conocimientos e instantáneamente decodificarlos en el mundo de los símbolos, las palabras, los códigos verbales y no verbales.

Para Bakhtin, el sujeto aprende y construye la realidad, le da sentido a su vida, basándose en su relación con lo social y con el otro, y esto está impregnado de lenguaje. Por lo tanto, lo social es responsable de la construcción del lenguaje - esencial en la construcción del conocimiento. "Cada pensamiento se procesa a través de signos. Cualquier pensamiento es la continuación de otro, para continuar en otro. El Pensamiento es diálogo" (Santaella, 2000, p.9). La producción de ideas en los textos siempre tiene un carácter colectivo, social. De manera, que son palabras e ideas las que entretejen el pensamiento.

La escritura no está desconectada de la vida, del contexto real de su enunciación, establece una relación inseparable entre lo lingüístico y lo social, el significado de la palabra está determinado por el contexto. En este sentido, Bakhtin señala que un texto es la realidad inmediata con la que se puede construir al pensamiento y a la experiencia, la textura del texto solo cobra vida en contacto con otro texto. Por lo tanto, las producciones de cartas están en constante interrelación.

\subsection{Cartas a favor del lenguaje}

De esta manera, los textos epistolares son unidades significativas que escenifican situaciones comunicativas. Leerlos y comprenderlos implica llenar vacíos, relatar discursos, establecer relaciones intertextuales. Interpreta quién produce una lectura a partir de la posición anticipadamente prevista por el texto para el destinatario; entiende quién problematiza esta posición, explicando y cuestionando el posicionamiento enunciativo del texto. El lenguaje pasa por tanto a ser observado como dialógico, ideológico e intertextual. Las cartas exploran el lenguaje, tratan los temas más diversos, a veces con sentimentalismo, pero siempre con conocimiento de causa, dirigiéndose al lector; revelando impresiones, opiniones y comprensión de los temas mientras pertenece a un determinado contexto.

Grandes cartas marcaron la historia de la humanidad. Las cartas del sabio Séneca. Las epístolas de San Pablo. Las cartas de Abelardo y Eloísa, cuya pasión fue brutalmente interrumpida. La carta de Pero Vãz de Caminha (Pedro Vaz de Caminha) habla sobre "la tierra de una manera tan graciosa". La carta en la que Sir. Walter Raleigh, a punto de ser ejecutado, le dice adiós a su esposa ("Te mando mi amor, para que lo guardes, cuando me encuentre muerto"). Las cartas de Sóror Mariana Alcoforado, testimonio del amor 
prohibido de la monja portuguesa con un oficial de caballería. Las cartas de Van Gogh a su hermano Theo. Cartas a un joven poeta, de Rilke. Las cartas escritas desde los campos de concentración. Textos conmovedores, que nos erizan, sino por la forma literaria por la autenticidad (Scliar, 2003, s/p)

El lenguaje, traducido en cartas, está al servicio del hombre, lo transporta de la ficción a la realidad o viceversa, le da al lector la capacidad de ser múltiple, de alcanzar dimensiones político-económicas, de cruzar barreras geográficas, de unificar o dividir credos religiosos, culturales o étnicos. Producir y escribir la propia historia es el medio por el cual el ser humano puede expresarse, defender sus ideas y finalmente interactuar con el otro. "La carta enviada actúa, en virtud del gesto mismo de la escritura, sobre quien la envía, tal como actúa, leyendo y releyendo, sobre quien la recibe" (Foucault, 1992, p. 145). A través de la mediación del lenguaje los valores ideológicos y culturales del mundo, y de las personas son construidos y/o reproducidos.

Y el lenguaje es realmente un océano: fluido, inestable, de contornos imprecisos, multiforme, impredecible, incontable, misterioso, lleno de playas agradables, pero también con olas gigantes y maremotos que nos hacen naufragar. El lenguaje es la lengua sobre todo, es la lengua más el mundo. La lengua es un pájaro relleno; el lenguaje es un pájaro vivo, suelto, volando por ahí (Bagno, 2001, p.307)

La escritura, como medio de comunicación del hombre, revela el valor de aprender por medio de su uso, ella hace posible que se pueda ampliar la visión limitada del mundo que construimos. Al utilizar la carta como recurso didáctico en el aula, se crea una interacción entre ficción y realidad, con el objetivo de profundizar en las actividades que implican procesos de lectura y escritura, por consiguiente representa desarrollar una reflexión sobre el lenguaje. La creación de situaciones reales de interacción discursiva permite a los estudiantes participar de manera efectiva en el proceso de construcción (reconstrucción) del conocimiento, aplicar significativamente los conceptos de texto y textualidad, agrega valores a un universo ficticio reflejado en una vida más real. Para Fiorin (2003, p.181), la interdiscursividad configura la incorporación de recorridos temáticos en otros discursos, de ahí la incorporación de significados en la escritura. Las cartas representan un espacio de libertad, oportunidad de intercambio, posibilidades de interacción, construcción de una relación interactiva; el lector luego configura el significado de lo que se escribió desde su perspectiva interpretativa.

\section{ARTE LITERARIO E INTERACCIÓN COMUNICATIVA}

Los diversos personajes que habitan la imaginación humana experimentan conflictos y ansiedades como el miedo, el amor, el deseo, la venganza, el odio, el orgullo e incluso la muerte. Es un universo particular que se abre a las múltiples facetas (posibilidades) de una misma palabra. El arte literario es la práctica capaz de formar un lector crítico, proporcionando reflexión y análisis, también es responsable de hacer que las personas sientan a través de la emoción, de los sueños, de la libertad de quienes escriben y de quienes leen, al adquirir más experiencia, ampliando los horizontes de las elecciones, cobra vida y se convierte en una personalidad que respira individualmente, cuando es percibida por el lector, quien establece una relación interactiva con él. 
Cuestiones sobre enseñanza de literatura o de lectura literaria envuelve, por tanto, un ejercicio de reconocimiento de las singularidades y las propiedades propositivas que dan forma a un tipo particular de escritura. Con esto, es posible eliminar una serie de errores que generalmente están presentes en la escuela en relación con los textos literarios, es decir, tratarlos como expedientes para servir a la enseñanza de buenos modales, hábitos de higiene, deberes ciudadanos, temas gramaticales, recetas desgastadas del "placer de texto", etc. Dicho de manera descontextualizada, tales procedimientos contribuyen poco o nada a la formación de lectores capaces de reconocer las sutilezas, las particularidades, los sentidos, la extensión y la profundidad de las construcciones literarias (Brasil, 1997, p. 30)

Guimarães Rosa, escritor de Minas Gerais, es un recreador del lenguaje, busca en las raíces regionalistas formas para traducir, con rasgos universales, problemas sociales, metafísicos y existenciales típicos de la vida de cualquier ser humano. En narraciones llenas de imágenes y situaciones sensoriales, recrea temas universales inspirados en la cultura popular, explora el lenguaje natural de los personajes, explorando en neologismos y significados, pero con la capacidad para revelar la verdadera esencia de los seres humanos. Rosa teje una constante interlocución con su lector, haciéndolo sentir inquieto e instigándolo a descubrir los misterios revelados por el lenguaje. "Si quieres seguirme, te lo diré; no en una aventura, sino en una experiencia, a la que induciré alternativamente, una serie de razonamientos e intuiciones" (Rosa, 1964, p.77).

Rosa combina, en sus narrativas la reconstrucción de ambientes y costumbres regionales del pasado con un tejido literario que crea y expande tramas para componer las historias de sus personajes, inmersos en valores sociales y humanos actuales; se fusionan temáticas que revelan las dimensiones universales en el sentido de centrarse en los dramas humanos más allá de las fronteras geográficas, siendo metáforas para que el lector se reconozca a sí mismo. Guimarães idealizo el Sertão (1) (interior) distante a través del lenguaje, exploró los misterios del ser humano desde contextos rurales, pero, paradójicamente, problematizó cuestiones universales. El mundo conocía el Sertão y el Sertão ganó el mundo. Para ello, mantuvo una estrecha comunicación con el traductor italiano Bizzarri a través de cartas, ya que la correspondencia entre ellos daría como resultado no solo la traducción literal de las palabras, sino también la interpretación que extrapola las definiciones y busca los efectos del significado.

El empoderamiento del lenguaje en la obra Rosiana revela temáticas significativas que van desde la muerte hasta la vitalidad de la existencia, para expresar mejor su proceso creativo, Rosa también mantuvo correspondencia con su traductor alemán Curt MeyerClason. En una de sus cartas a Bizzarri, revela su preocupación por escribir sobre los desafíos que anhelan los humanos.

Cuando escribí, no fue partiendo de presupuestos intelectuales, ni seguí ninguna planificación cerebral deliberada. Por el contrario, todo, o casi todo, era una efervescencia del caos, un trabajo casi profético y una elaboración subconsciente. Luego, después de que el libro estuvo listo y publicado, encontré mucho en él; a veces cosas que se habían unido por sí mismas, muchas milagrosamente. Muchos elementos del libro y otras cosas de mí mismo (Rosa, 2003, p.89)

Sin embargo, Manuel Bandeira también consagrado autor del modernismo brasilero, le pregunta en una carta sobre la perspicacia con la que logra explorar las 
expresiones del interior de Minas Gerais y de su forma singular, con la cual consigue alcanzar las raíces del lenguaje de manera profunda, para traducir saberes y experiencias de la vida cotidiana.

Después, continuaron diciendo que habías inventado un nuevo idioma y que no me gusta un idioma inventado. Siempre renegué de esperantos y volapuques. Verás, Riobaldo no es un idioma nuevo. A veces es difícil. ¡Cuánta palabra del sertão (interior)! Al principio, muy diligentemente, iba a buscar significado en el diccionario. No pude encontrar nada (Bandeira, 1967, p.590).

En su carta, Bandeira revela que leer la obra Rosiana requiere la búsqueda de la palabra en su carácter dinámico, evadiendo los estereotipos y los patrones lingüísticos, es una reinvención del lenguaje.

Solo creo que no necesitaba contarlo de una forma explosiva, como Joyce en el último capítulo de Ulises, las 594 páginas de la historia de Riobaldo. ¿Cuántas horas tomaría? Me tomó días leer. Me alegra que lo hayas dicho todo, minuciosamente. Y el caso de Diadorim, ¿fue posible? Eres general, lo sabes. Pero tuve mi decepción cuando se descubrió que Diadorim era una mujer. Honni soit qui mal pensé, creo que prefería al hombre Diadorim hasta el final. ¡Qué bien lo disfrazaste! Nunca imagine algo malo (Bandeira, 1967, p.591)

De esta forma, al explorar las diversas facetas del lenguaje, ya sea debido a su estructura argumentativa o su carácter épico, trabajar con clases de secundaria utilizando de forma creativa la palabra, para mejorar la exploración del sentido figurativo y sugestivo de las formas de expresión de un narrador consciente, capaz de establecer un vínculo entre el lenguaje de los textos literarios y la producción escrita que se fundamenta a partir de un argumento el cual finaliza con las más diversas formas de conocimiento. Según Cosson (2006, p.17), "la experiencia de la literatura no solo nos permite conocer la vida a través de la experiencia del otro, sino también experimentar esa experiencia". Las múltiples formas de explorar el lenguaje y traducir innumerables pensamientos fueron medios de comunicación entre los jóvenes adolescentes del siglo actual y las obras y experiencias de Guimarães Rosa.

Al igual que Bandeira y Rosa, el trabajo didáctico con las cartas resultó en el tejido de correspondencias inusuales que provocan nuevas miradas y perspectivas sobre el lenguaje, la práctica literaria y las experiencias, pueden ser leídas en la totalidad de las cartas que se presentarán en la siguiente sección de este artículo.

Estas cartas fueron parte del Proyecto "El Sert(ão) de cada uno" (El Interior de cada uno) desarrollado en 2018 como uma práctica docente de portugués con estudiantes de secundaria, durante tres meses, en la Escuela Estatal Padre Paulo, en el interior de Minas Gerais, Brasil. Este proyecto fue premiado por la Fundación Víctor Civita; "Premio Educador Nota 10" en 2018, el resumen se puede ver en el sitio web del premio a través del enlace: https://www.youtube.com/watch? $\mathrm{v}=\mathrm{Mbf}$ ZZlW6KdM y en el sitio web de la revista Nueva Escuela. Las historias Rosianas contadas por los estudiantes y el redescubrimiento del (ser) de cada uno también fueron reconocidas por la Academia de Letras João Guimarães Rosa con el trofeo Capitán-Doctor João Guimarães Rosa en 2019, en una ceremonia celebrada en la fecha conmemorativa del "fallecimiento" del autor. 


\subsection{Cartas para Guimarães Rosa, Interacciones y Pluralidad discursiva}

El origen del Proyecto "Ser (tão) de cada uno" surgió a partir de las observaciones como profesora de lengua portuguesa en relación con las dificultades de los estudiantes para desarrollar el hábito de lectura, especialmente en relación con la literatura brasilera. De esta manera, durante el período de tres meses, se propusieron varias actividades y producciones orales y escritas con los estudiantes para que lograran escribir cartas a Guimarães Rosa, un escritor considerado como difícil de leer en Brasil, debido al hecho de que emplea términos inusuales en el idioma portugués. La intención era hacer que los estudiantes percibieran dentro de las narrativas Rosianas las representaciones simbólicas y las posibilidades que la literatura trae metafóricamente de las realidades.

El proceso de creación de las cartas se llevó a cabo en las clases de literatura de la escuela, en momentos extraescolares y tuvo varias etapas para la producción de las mismas. La diversidad cultural podría identificarse, inicialmente, a través de un diagnóstico realizado. La primera propuesta fue leer un fragmento del cuento "Famigerado" de João Guimarães Rosa, la narrativa se inserta en la obra Primeiras Estórias (Primeras Historias). También leyeron un fragmento tomado de la obra Grande sertão: veredas en los que deben observar que el narrador hace los relatos a un interlocutor que solo se percibe a través de las alusiones hechas por el narrador mismo. El narrador presenta una tesis que se fundamenta en un argumento que termina con una conclusión sobre el mal que se internaliza en los seres, en las cosas y también afirma qué podría luchar contra ese mismo mal, el demonio interno de cada uno. A través de un discurso intertextual, tales elementos se perciben en la obra de Caricaturas Grande Sertão: Veredas - El diablo en la calle en medio del remolino.

Una de las mayores dificultades observadas fue la comprensión del vocabulario, a pesar del tono poético, está marcado por la oralidad, por palabras desconocidas. En un segundo momento, titulado "El conocimiento del pueblo bajo la mirada Rosiana" percibiendo la dificultad de comprensión de los estudiantes respeto al lenguaje y el tratamiento del tema por Guimarães, el trabajo con la "Carta de Manuel Bandeira". El romance de Riobaldo fue esencial para que sintieran cuán profundo es el trabajo en cuestión y la importancia del autor de Minas Gerais para la lectura de una sociedad, que los temas abordados no están desarticulados, sintetizan conflictos y enseñanzas. Fue necesario profundizar en la esencia dialógica propuesta por Riobaldo y Diadorim, con análisis y discusiones del texto Aforismos en Grande Sertão: veredas.

El tercer momento, fue denominado Diálogos con el Modernismo: cada grupo de estudiantes eligió un cuento de Guimarães para leer, contextualizar y explicar a los otros colegas dónde vivía el valor atemporal presentado por el autor. En cada exposición oral, dado que la variación entre las obras difiere no solo por el uso diferenciado de los materiales, sino también por el contexto que describe el pensamiento del hombre, los estudiantes deben sintetizar la idea principal de la trama, delinear la estructura narrativa seguida por el autor, contextualizar y relacionar la historia con el mundo actual.

A titulo de ilustración de lo que hicieron, es posible percibir la personificación de Burrinho Pedrês en la que fueron capaces de relacionar la sabiduría en la vejez con los ancianos que están desacreditados, tal como sucedió con el burrito; otra historia fue San Marcos, los hechiceros y curanderos que también eran comunes en la ciudad fueron reconocidos en el hechicero João Mangolô; en la Tercera Orilla del Río, buscaron información y concluyeron que un río solo tiene dos orillas, la tercera es la de aislamiento que puede ocurrir dentro de sus propios hogares. En el cuarto momento, disfrute cuando 
fueron realizadas interlocuciones entre la obra, el autor y el lector, en las que se discutió la extrañeza, el surgimiento de dudas, así como una forma de intercambiar conocimiento y resignificar la información, la metáfora de una época.

En ese momento los estudiantes produjeron el stop motion. Para finalizar, el quinto momento fue considerado para comprender la sociedad, los estudiantes aprendieron a leer imágenes, entrenaron sus ojos para ser sensibles y siempre buscaron una relación con el trabajo de Guimarães Rosa. Fotografiaron habitantes de la ciudad, entornos o situaciones que los informaron sobre un universo particular que, como el arte, difunde y refleja una idea, traduce una opinión, convierte la vida cotidiana en ideología. A modo de ejemplo el registro que hizo, se observa en los cobertizos de una fábrica de fuegos artificiales, el simbolismo de la travesía diaria de aquellos que se van a trabajar, pero no saben lo que pueda acontecer, conviven diariamente con el miedo. La cruz fotografiada en una tumba en el cementerio local con las palabras relacionadas con el cuento A Menina de Lá (La niña de allá), La muerte es algo que nadie quiere, pero nadie escapa. Es inevitable en la vida de cualquier ser. ¿Pero quién querría su propio ataúd?

La construcción de una sociedad justa se basa en la equidad y la sensibilidad, a menudo traducida en el contexto ficticio y el (ser)tão que hay en cada uno. La participación de los estudiantes en las obras de Guimarães Rosa y los resultados de la producción de las cartas de los estudiantes demostraron una motivación expresiva de los estudiantes para la escritura, con la literatura brasilera y brindaron la oportunidad de una pluralidad discursiva, como es posible evidenciar en las cartas estos alumnos.

En esta primera carta seleccionada, la estudiante presenta sus curiosidades y extrañezas de la compleja escritura de Guimarães Rosa, describe las nuevas informaciones aprendidas de la lectura de su trabajo.

Santo Antônio do Monte - MG, 23 de mayo de 2018

Querido Guimarães Rosa, mi ya íntimo escrito.

Debo decir y confesar que nunca había leído un cuento suyo, pero los cambios son necesarios incluso aquellos que nos causan miedo al principio, como por ejemplo el cambio de las maestras de portugués. Pero no vine a través de esta carta a traer lamentaciones sobre mi nueva y exigente profesora de lenguaje, sino por su increíble y triste historia del cuento "la niña de allá".

Confieso que algunas palabras me fueron difíciles de entender, como cuando mencionaste que la madre de María era Urucaiana, me llevó horas descubrir que Urucuía es un pueblo minero (Minas Gerais) y que la madre de Nhinhinha era de ese municipio.

Pero cambiando de tema, tuve una "rechazo" por parte de los padres de la pequeña María, no la dejaron expresarse, simplemente porque era diferente, y eso me mató, en mi corazón, y creo que también estaba matando a Nhinhinha.

Y nuestra Guimarães, este final tuyo me dejó muy conmocionado, porque mi persona es un poco experta en idealizar parejas, esperaba que hubieras tenido un resultado diferente, donde María crecería y encontraría su libertad, no la muerte, sino el amor ,que no es necesariamente de un hombre, sino de amigos e incluso de su propia familia.

Pero con este sorprendente final, finalmente logré entender a Nhinhinha, para mí ella era un ser espiritual, por lo que nadie entendió lo que estaba diciendo y fue la misma razón por la que contempló la naturaleza y porque se cumplieron sus deseos.

La dulce y pequeña Nhinhinha, como ya había mencionado, encontró su libertad en la muerte, regresando a su verdadero hogar, pero la niña era tan maravillosa que incluso sabiendo que iba a volver a casa, cumplió el último deseo de sus padres, trayendo lluvia 
de regreso y salvando el Sertão de la sequía, así que pensé que era seguro que su último deseo (el ataúd rosa con piedras verdes) sería concedido.

Su cuento me encantó y tu escritura me cautivó, espero que me lleve un tiempo encontrarte, espero que estés bien y feliz, tal vez incluso en el mismo lugar donde Nhinhinha fue.

Con cariño, tu fiel amiga y compañera.

En esta segunda carta, se observan situaciones similares a la anterior, como las dificultades para comprender la complejidad de la escritura de Guimarães Rosa, la participación y la búsqueda de intimidad con el autor, el uso de palabras contemporáneas para el diálogo con el mismo.

Santo Antônio do Monte, 23 de mayo de 2018.

Estimado desconocido, J. Guimarães Rosa, ¡Reciba nuestros saludos!

Digamos que es bastante complicado aclarar tal apreciación cuando se trata de algo escrito por usted. Después de leer su cuento: "Secuencia", reuniendo todas las opiniones del grupo de envío, me siento halagado de representarlos adjuntándolos aquí.

¡Cuánto trabajo, no!

Tú siempre nos das esa lectura complicada, por lo tanto horripilante. Estoy impresionado por tu capacidad singular de expresarte tan fácilmente entre tus diversas obras.

Al analizar la situación del hijo de Seu Rigério, supongo que eres muy aficionado a los juegos que el destino puede hacer a aquellos que siguen el viaje sin temor, incluso si no hay un resultado esperado del esfuerzo realizado.

Una vez más, demuestro, tanta admiración por su singularidad. Lo que a su vez te da muchos créditos de tus lectores. El uso de sus palabras, sean conocidas o no, se presenta de una manera muy interesante. También es notable su enorme talento para el uso del neologismo, dando la impresión de que fue creado exclusivamente para su uso personal. Palabras complicadas Pero sino, algo estaría mal. Su precisión compleja lo hace interesante, haciéndonos entrar cada vez más en esta historia.

Es una pena decir que, en el transcurso del trabajo, algunas cosas se volvieron difíciles de entender, creando la duda de cómo el niño abordó su amor. Depende de usted explicar mejor los hechos, porque con palabras tan complicadas, el discernimiento se vuelve incierto.

Ese es el mayor o el peor de los errores e imprudencias, después de todo, ¿quién soy yo para hablar sobre lo que sucede en el pensamiento de cada uno? Para ser sincero, un "nadie".

Pero, de hecho, creo que la verdadera necesidad de mostrar lo que sientes o piensas es una buena razón para escribir historias como esa. Porque, ¿cómo podría ser posible desatar pensamientos tan intensos sobre el curso de la vida si no fuera con una bella historia con esa buena y vieja moral al final de todo?

Te admiro Querido Guimarães.

Por su sutileza al tratar con los hechos experimentados por todos. Después de todo, el destino es como una inmensa envoltura de la vida. Nunca imaginaba al niño encontrando su gran amor. Nunca imaginaremos lo que está por venir.

Podemos ser como un perro callejero que solo busca su libertad para volver a sus viejos lazos. O tal vez como Seu Rigério quien, al abandonar ese viaje, terminó encontrando mucho más de lo esperado. No sabemos. Tú tampoco. Ni yo. Por lo tanto, les dejo aquí mis sinceros saludos, esperando el próximo encanto provisto por sus buenas y viejas perspectivas. 
En esta tercera carta, es posible observar que el estudiante comenzó el diálogo como una búsqueda de acercamiento con Guimarães Rosa como si fueran "viejos amigos".

Querido amigo João Guimarães Rosa, ¿cómo estás?

Tuve un poco de tiempo libre, leyendo una de sus obras, el cuento Lunas de Miel, y tú, como siempre, haciéndonos entrar en el mundo del personaje para entender toda la historia. Cuantas palabras inventadas en este cuento, mi mente se abrió a una reflexión sobre el amor.

El amor, algo tan hermoso y, al mismo tiempo, tan complejo, puede curar un dolor o romper un alma de tanta desilusión, amor doloroso, amor entre el hijo y sus padres, la esposa y el marido, amores duraderos o amores con las estaciones que van y viene, amores prohibidos.

¡Ah! ¡El amor! Como es complejo, pero además un amor verdadero nunca desaparece, como en la historia de Seu Seotaziano y Sá-Maria Andreza, un matrimonio de largos años, vida sencilla en la granja, con esa monotonía sin algo diferente y que hizo que su amor se enfriara y dejara de ser cálido.

Hasta que recibieron una carta de un viejo amigo, el mayor João Dioclécio, una pareja de novios iba a huir, e la novia era su hija y les pidió que los llevaran a su granja, el amor joven y prohibido causó las llamas del amor de Seu Seotaziano y Sá-Maria Andreza, de tal manera se reaviva.

Bueno, me encanta leer tus cuentos, sin embargo, creo que en esta historia no debería haber aceptación de su padre o de la familia por parte de la novia. En el momento en que el hermano de la novia la encontrara, habría una confrontación entre él y el novio, quien terminaría muerto en los brazos de su amada, relatando un amor fuerte pero distante.

Pero... jes el amor!

$\mathrm{Su}$ fiel lectora

En la cuarta carta, reaparecen temas universales como el amor, la amistad, la lealtad, la traición, los temas de la literatura de ayer y de hoy.

Querido J. Guimarães Rosa, ¿cómo es la vida en el sertão (interior)?

Leí una preciosa historia tuya llamada La vela al diablo, ese vocabulario diferente y difícil de entender porque tiene su propio lenguaje interior. Pero, curiosamente, inmerso en lo cotidiano con mezclas de sentimientos encontrados en los pensamientos del personaje de Teresinho.

Es sorprendente que Teresinho no haya engañado a Zidica con Dlena. ¡Aaaah! ¡Guimarães! Me sorprendería si viviera en ese tiempo cuando la gente no tenía relaciones más íntimas.

Sin embargo, tenía curiosidad, ¿cuál es el verdadero sentimiento de Dlena, realmente tenía amor por Teresino o es como las chicas de hoy que siempre quieren interrumpir el cortejo de alguien para tener el hombre que quieren?

Me impresionó la lealtad que tenía al elegir su amor como la mejor opción, ya que muestra el verdadero amor que hoy, es raro de ver.

Como dije, el pensamiento de Teresinho es muy abierto, pero ¿dónde está el de Zidica? Si fuera hoy, la mujer ya habría ido a buscar a su hombre e hizo una "tienda", tomando la posición de no salir como una tonta o retrasada o incluso con un corazón suave, como dicen aquí, sin importar cuánto no lo fuera. Quede con la siguiente pregunta, realmente confiaba en él o vivía en... "deja que la vida me lleve, la vida me lleva a mí..".

La historia gira en torno a Teresinho, quería saber más sobre las chicas, si se conocían, qué pensaban cada una. 
Sin embargo, me veo obligado a decir que su trama fue maravillosa y podría tener la segunda temporada... jajaja... iEntonces, fue un gran placer leer una de sus obras!

Un fuerte abrazo para ti, maravilloso autor de la historia brasilera.

A partir de estas cartas, es posible observar que la escritura epistolar, en este contexto, refuerza el discurso que se refiere a las especificidades de los interlocutores, uno debe considerar las propias creencias, opiniones y conocimientos; como formas para superar los límites del lenguaje y recrear experiencias. Una estrategia de enseñanza que aprovecha los recursos literarios, para proporcionar autonomía sin separarse de las dimensiones político-económicas, barreras geográficas; se configura como un mecanismo para legitimar el pensamiento humano, para unificar credos religiosos, la cultura o el origen étnico. Según Candido (1989, p.113) "Los valores que defiende la sociedad, y aquellos que considera perjudiciales, están presentes en las diversas manifestaciones de ficción, poesía y acción dramática. La literatura confirma y niega, propone y denuncia, apoya y lucha, brindando la posibilidad de experimentar dialécticamente problemas"

Al trabajar y percibir la literatura como un arte multidisciplinar que tiende a valorar el proceso creativo, la necesidad de ritualizar los comportamientos y las esferas sociales, que codifica y dialoga con la realidad y el contexto, es posible hacer que las ideas y pensamientos explícitos estén sujetos a nuevas preguntas, la visión se amplía en relación con las diversas formas de expresión.

La actividad de la escritura se presenta, por lo tanto, como el momento de mostrarse, darse a ver y hacer que aparezca el rostro junto con los otros. Y debe entenderse de tal manera que la carta es simultáneamente una mirada que regresa al destinatario (a través de la carta que recibe, se siente observado) y una manera para que el remitente se ofrezca a su mirada, por lo que de sí mismo le dice (Foucault, 1992, p.8)

El diálogo entre la obra, el autor y el lector presupone no solo la extrañeza, el surgimiento de dudas, sino también una forma de interacción entre el conocimiento y la información, la abstracción y las metáforas de un período histórico.

\section{CONSIDERACIONES FINALES}

El lenguaje implica la materialización del pensamiento, se presenta como un instrumento de enunciación humana; cuando se traduce en palabras, a través de la escritura toma forma y da movilidad a los saberes más diversos. Una de las formas de su enunciación más directa entre los interlocutores, a lo largo de la historia se da través de cartas (misivas) que generalmente están abiertas a discusiones dialógicas constantes. El locutor permite ser conocido, quizás, íntimamente, a través de signos lingüísticos que lo representan. Por otro lado, deja espacios que su interlocutor llenará.

Al desencadenar textos discursivos que exploran el arte literario, en el que las metáforas dan forma a los anhelos y las experiencias en todos y cada uno de los órdenes, los textos epistolares obtienen aún más evidencia, ya que pueden ser alusivos a las más duras y tristes realidades, así como expresar la mayoría de sentimientos sutiles y nobles. Por lo tanto, cuando se establece una conexión entre el lenguaje literario y la capacidad humana para comunicarse, especialmente a través de las cartas, pueden surgir y experimentar nuevas y curiosas impresiones. 
Notas

(1) En Brasil, Sertão proviene de un termino empleado para referirse a una vasta región geográfica, lo cual en términos del escritor Guimarães Rosa hace referencia a un espacio Nordestino Brasileño y se designa en relación con la población del interior.

\section{REFERENCIAS BIBLIOGRÁFICAS}

Bagno, M. (2001). Dramática da língua portuguesa: Tradição gramatical, mídia e exclusão social. São Paulo: Loyola.

Bakhtin, M. (1997). Marxismo e filosofia da linguagem. São Paulo: Hucitec.

Bandeira, M. (1967). Grande sertão: veredas. Em Poesia Completa e Prosa (pp.590592). Rio de Janeiro: Aguilar.

Bizzarri, E. (2003). João Guimarães Rosa-Correspondência com seu tradutor italiano. São Paulo: Nova Fronteira.

Brasil (1997). Ministério da Educação. Secretaria de Educação Fundamental. Parâmetros curriculares nacionais: língua portuguesa - Ensino de primeira à quarta série. Brasília.

Campos, F. y Miranda, R. (2005). A escrita da história. São Paulo: Escala Educacional.

Candido, A. (1989). Direitos Humanos e literatura. En A.C.R. Fester (Org.) Direitos humanos E... Brasil: Cjp / Ed. Brasiliense

Cecílio, C. (2019). Como usar Guimarães Rosa para despertar a vontade de ler e escrever. São Paulo: Revista Nova Escola. Disponible en: https://novaescola.org.br/conteudo/18389/como-usar-guimaraes-rosa-paradespertar-nos-alunos-a-vontade-de-ler-e-escrever

Cosson, R. (2006). Letramento literário: teoria e prática. São Paulo: Contexto.

Dionisio, A. y Bezerra, M. (2003) (Orgs.). O livro didático de português: Múltiplos olhares. Rio de Janeiro: Lucena.

Dionisio, A., Machado, A. y Bezerra, M. (Org.). Gêneros textuais e ensino. Rio de Janeiro: Lucena.

Fenske, E. (2018). Aforismos em Grande Sertão: veredas. 2015. Disponible en: http://www.elfikurten.com.br/2011/01/grande-sertao-veredas-aforismos.html

Fiorin, J. (2003). Polifonia textual e discursiva. En D. L, Barros y J. Fiorin (Orgs). Dialogismo, polifonia e intertextualidade. (pp. 181-182) São Paulo: Edusp.

Foucault, M. (1987). As palavras e as coisas: uma arqueologia das ciências humanas. São Paulo: Martins Fontes.

Foucault, M. (1992). A escrita de si. En O que é um autor? (129-160). Lisboa: Passagens.

Guazzelli, E. (2018). Grande Sertão: Veredas-Graphic Novel-Quadrinhos. João Guimarães Rosa. Editora: Globo Livros Graphics.

Guimarães Rosa. J. (1976). Grande sertão: veredas. Rio de Janeiro: José Olympio.

Guimarães Rosa. J. (1979). Sagarana. Rio de Janeiro: José Olympio.

Guimarães Rosa. J. (2001). Primeiras estórias. Rio de Janeiro: Nova Fronteira.

Guimarães Rosa. J. (2003). João. Correspondência com seu tradutor alemão Curt MeyerClason: (1958-1967). Rio de Janeiro: Nova Fronteira: Academia Brasileira de Letras; Belo Horizonte, MG: Ed. da UFMG.

Santaella, L. (2000). A Teoria Geral dos Signos: como as linguagens significam as coisas. São Paulo: Pioneira.

Scliar, M. (2003). A arte de escrever cartas. 2003. s/p. Disponible en: https://www.cartamaior.com.br/?/Editoria/Midia-e-Redes-Sociais/A-arte-deescrever-cartas/12/4350

e-ISSN:2172-7910

Doi: http://doi.org/10.25267/Hachetetepe.2020.i20.6

Universidad de Cádiz 